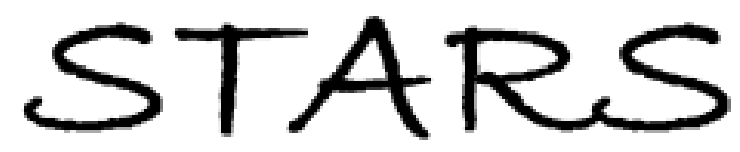

University of Central Florida

STARS

$1-1-2003$

\title{
Physical and optical properties of sol-gel nano-silver doped silica film on glass substrate as a function of heat-treatment temperature
}

\author{
Wenyan Li \\ University of Central Florida \\ Sudipta Seal \\ University of Central Florida \\ Edward Megan \\ University of Central Florida \\ Jeff Ramsdell \\ University of Central Florida

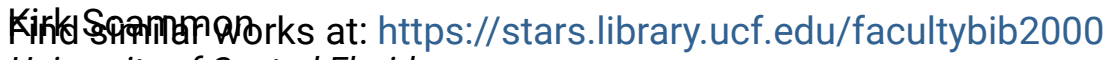 \\ University of fentral Flaridalda Libraries http://library.ucf.edu
}

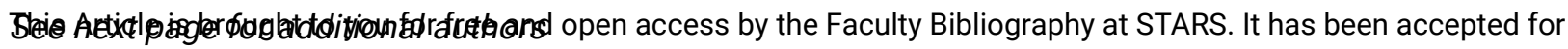
inclusion in Faculty Bibliography 2000s by an authorized administrator of STARS. For more information, please contact STARS@ucf.edu.

\section{Recommended Citation}

Li, Wenyan; Seal, Sudipta; Megan, Edward; Ramsdell, Jeff; Scammon, Kirk; Lelong, Gerlad; Lachal, Laurent; and Richardson, Kathleen A., "Physical and optical properties of sol-gel nano-silver doped silica film on glass substrate as a function of heat-treatment temperature" (2003). Faculty Bibliography 2000 s. 3886. https://stars.library.ucf.edu/facultybib2000/3886

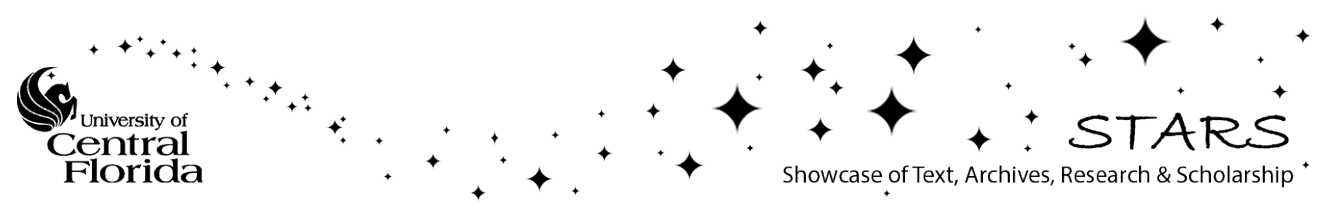




\section{Authors}

Wenyan Li, Sudipta Seal, Edward Megan, Jeff Ramsdell, Kirk Scammon, Gerlad Lelong, Laurent Lachal, and Kathleen A. Richardson 


\section{Physical and optical properties of sol- gel nano-silver doped silica film on glass substrate as a function of heat-treatment temperature}

Cite as: Journal of Applied Physics 93, 9553 (2003); https://doi.org/10.1063/1.1571215

Submitted: 12 December 2002 . Accepted: 12 March 2003 . Published Online: 30 May 2003

Wenyan Li, Sudipta Seal, Edward Megan, Jeff Ramsdell, Kirk Scammon, Gerald Lelong, Laurent Lachal, and Kathleen A. Richardson

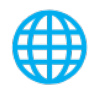

\section{ARTICLES YOU MAY BE INTERESTED IN}

Formation of copper and silver nanometer dimension clusters in silica by the sol-gel process Applied Physics Letters 68, 3820 (1996); https://doi.org/10.1063/1.116628

Shape effects in plasmon resonance of individual colloidal silver nanoparticles

The Journal of Chemical Physics 116, 6755 (2002); https://doi.org/10.1063/1.1462610

Sol-gel synthesized silver nanoparticles doped silica/titanosilicate films for plasmonic solar cell applications

AIP Conference Proceedings 1849, 020017 (2017); https://doi.org/10.1063/1.4984164

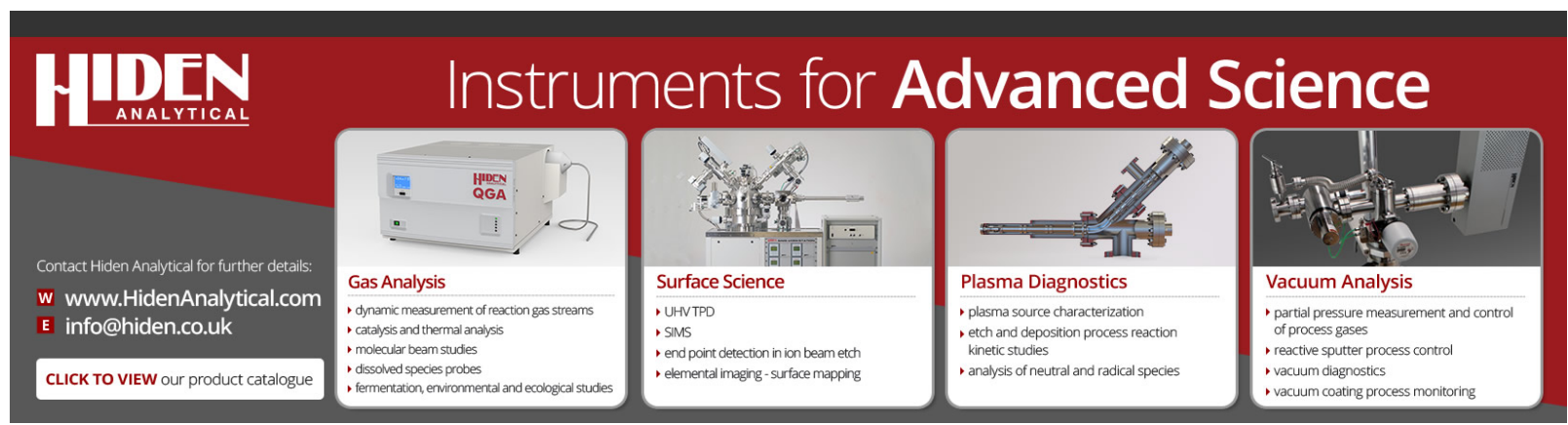




\title{
Physical and optical properties of sol-gel nano-silver doped silica film on glass substrate as a function of heat-treatment temperature
}

\author{
Wenyan Li, Sudipta Seal, ${ }^{a}$ Edward Megan, Jeff Ramsdell, and Kirk Scammon \\ Advanced Materials Processing and Analysis Center and Mechanical, Materials and Aerospace Engineering \\ Department, University of Central Florida, Orlando, Florida 32816 \\ Gerald Lelong \\ Institute of Chemistry of the Condensed Matter of Bordeaux, University of Bordeaux I, 33405 Talence \\ cedex, France

\begin{abstract}
Laurent Lachal
Education and Research Unit, Physics Department, University of Claude Bernard, 69622 Villeurbanne
\end{abstract} \\ cedex, France \\ Kathleen A. Richardson \\ School of Optics and The Center for Research and Education in Optics and Lasers, Advanced Materials \\ Processing and Analysis Center and Mechanical, Materials and Aerospace Engineering Department, \\ University of Central Florida, Orlando, Florida 32816
}

(Received 12 December 2002; accepted 12 March 2003)

\begin{abstract}
Nano-silver doped silica films were deposited on glass slides using a sol-gel process and heat-treated at different temperatures. The films were characterized by ultraviolet-visible spectroscopy, $\mathrm{x}$-ray photoelectron spectroscopy (XPS), atomic force microscopy (AFM), Rutherford backscattering spectrometry (RBS), and transmission electron microscopy for their optical, chemical, and structural properties. The absorption peak of silver colloids (wavelength from 400 to $460 \mathrm{~nm}$ ) was present and a blueshift and intensity reduction of the absorption peak was observed during heat-treatment. Particle size reduction and surface morphology changes in the films were observed by AFM as a function of varying heat treatment temperatures. Silver nanoparticles were formed through spontaneous reduction of silver ions. The oxidation of silver occurs during heat-treatment, causing a reduction of absorption intensity. An interdiffusion between the $\mathrm{Ag}$ in the film and $\mathrm{Na}$ in the substrate glass was observed by XPS and RBS. Sodium in the coating likely increased the stability of silver oxide at high temperature treated samples. (c) 2003 American Institute of Physics.
\end{abstract}

[DOI: $10.1063 / 1.1571215$ ]

\section{INTRODUCTION}

Optical properties of composites consisting of nanometer-sized metal particles dispersed in solid dielectric materials, such as glass, have been of increasing interest because of their important optical applications. Colloidal gold and silver have been used in a stain-glass technique since the medieval age, as their absorption spectra exhibit extinction bands in the visible region and bring beautiful colors to the glasses. ${ }^{1}$ Photochromic glasses containing silver and copper halides were developed by Corning in the early 1960s. ${ }^{2}$ In the last two decades, composite materials containing metal nanoparticles have attracted much attention because of their potential application in nonlinear optics. ${ }^{3-7}$

Noble metal clusters can be introduced into a glass matrix through different methods such as the traditional melt quenching method, ion implantation, ${ }^{8,9}$ ion exchange, ${ }^{10,11}$ and the sol-gel technique. ${ }^{12-14}$ In recent years, sol-gel synthesis of nano-composites containing ultrafine particles of noble metals in oxide matrices has been rapidly developed. Sol-gel is becoming one of the most useful and versatile

\footnotetext{
a) Author to whom correspondence should be addressed; electronic mail: sseal@pegasus.cc.ucf.edu
}

methods of oxide film fabrication due to the following advantages: low-processing temperature, homogeneity of coatings, easy control of metal concentration and coating thickness, as well as the possibility to add reducing and oxidizing agents in small concentrations. ${ }^{15,16}$

Different metal particles were prepared in glassy matrices by the sol-gel method, such as gold, ${ }^{17-25}$ copper, ${ }^{26,27}$ platinum, ${ }^{22,24,28}$ and silver. $^{12,16,17,21,22,29-33}$ Silver particles have been incorporated by dissolving silver salts in the precursor sols and reduction of the silver ions to metallic particles by thermal treatment in air or in an hydrogen atmosphere, or by irradiation with UV light or gamma rays.

During the formation of $\mathrm{Ag}$ colloids in a thermal treatment, temperature is critical for the silver particle size and the oxidation/reduction reaction of silver. It will affect the optical density and absorption wavelength of silver colloids. While silver-containing sol-gel films and gels are heated, reversible darkening is observed. Some suggest this darkeningbleaching effect is due to an aggregation-disaggregation of silver particles, ${ }^{34}$ while others attribute this to reduction/ oxidation of silver colloids. ${ }^{35,36}$ The substrate being coated is also an important factor that influences the Ag colloid formation process. It seems that the silver colloids in a silica-based coating on the soda-lime glass substrate have a greater ten- 
dency towards being oxidized than those on a silica substrate. $^{35}$

In the present article, we report the incorporation of silver into silica-based sol-gel films on soda-lime glass substrates, following by optical measurements as a function of heat-treatment temperature, and these results are correlated to microstructural and chemical changes in the films.

\section{EXPERIMENT}

\section{A. Preparation of coatings}

Sol-gel silica thin film coatings containing silver particles were formed by dip-coating on glass microscope slides (Fisher scientific). The glass slide is made of soda-lime glass, with a composition (wt \%): $74.2 \mathrm{SiO}_{2}, 14.3 \mathrm{Na}_{2} \mathrm{O}, 6.4 \mathrm{CaO}$, $4.3 \mathrm{MgO}, 1.2 \mathrm{Al}_{2} \mathrm{O}_{3}, 1.2 \mathrm{~K}_{2} \mathrm{O}, 0.03 \mathrm{SO}_{3}$, and $0.03 \mathrm{Fe}_{4} \mathrm{O}_{3}$. The $\mathrm{SiO}_{2}-\mathrm{Ag}$ sol was prepared using tetraethyl orthosilicate (TEOS), $\mathrm{C}_{2} \mathrm{H}_{5} \mathrm{OH}, \mathrm{H}_{2} \mathrm{O}, \mathrm{HNO}_{3}$, and $\mathrm{AgNO}_{3}$ as precursors. First, solution $\mathrm{A}$ is prepared by mixing TEOS and ethanol in equal volume. Then, solution $\mathrm{B}$ is prepared by adding distilled water, different amounts of silver nitrate $\left(\mathrm{AgNO}_{3}\right)$, and nitric acid $\left(\mathrm{HNO}_{3}\right)$ together. $\mathrm{HNO}_{3}$ is added to adjust the $p \mathrm{H}$ to approximately 2 . Finally, solution B was added to solution A drop by drop while vigorously stirring at room temperature. The final molar ratio TEOS: $\mathrm{C}_{2} \mathrm{H}_{5} \mathrm{OH}: \mathrm{H}_{2} \mathrm{O}: \mathrm{AgNO}_{3}$ $=1: 3.825: 3: x$, where $x$ is the $\mathrm{Ag} / \mathrm{Si}$ molar ratio in the glass coating. Staring solutions with $\mathrm{Ag} / \mathrm{Si}$ molar ratio, $x$ $=0.05 \%, 0.1 \%, 0.2 \%, 0.5 \%, 1 \%$, and $2 \%$ were prepared. The $x$ value is used to label the silver concentration in the dried glass films.

Following mixing of two solutions, the sol was left to age until the viscosity reached approximately $3 \mathrm{cP}$. The viscosity of the solution was monitored by a Brookfield digital viscometer (model LVTD). It usually took 2-4 days for the sol to get ready, depending on the silver concentration, with sols with a higher silver concentration taking a shorter time. The influence of metal salts on the stability of the sol and the gelation process can be found in the literature. ${ }^{37}$ After the viscosity of the sol reached $3 \mathrm{cP}$, the coating was formed by dip-coating the glass slides at a pulling rate of $1 \mathrm{~mm}$ per second. All films were dried at $100^{\circ} \mathrm{C}$ for $1 \mathrm{~h}$ in an Isotemp Oven (Fisher Scientific), then heat-treated in air at different temperatures $\left(200,300,400\right.$, or $\left.500^{\circ} \mathrm{C}\right)$ for $2 \mathrm{~h}$ in a Thermolyne Furnace (Model 48000). The films prepared under such conditions showed no tendency toward cracking or peeling from the substrate.

\section{B. Nano silver cluster formation and film characterization}

Silver-containing silica sol and heat-treated coatings with $1 \% \mathrm{Ag}$ were characterized using transmission electron microscopy (TEM), scanning electron microscopy (SEM), atomic force microscopy (AFM), x-ray photoelectron spectroscopy (XPS), and Rutherford backscattering spectrometry (RBS).

HRTEM (FEI-Philips Tecnai F30) was used to study the formation of silver nanoparticles in the sol with $0.05 \% \mathrm{Ag}$. The TEM sample was prepared by dipping the copper grid into the sol diluted by acetone. After the solvent evaporated,

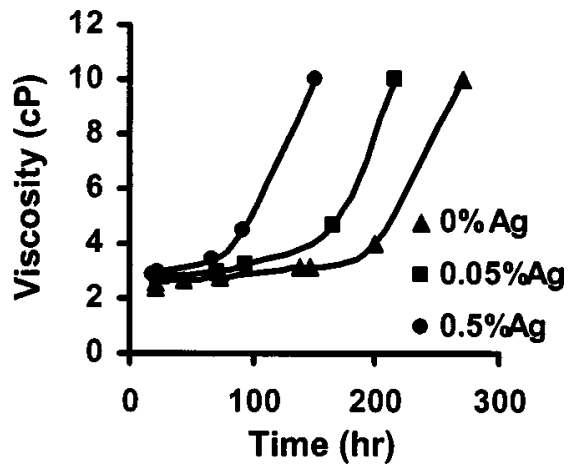

FIG. 1. Gelation curves for the silica systems with different silver concentration.

the silica sol gelled on the copper grid, with silver particles formed in the silica matrix. This is a parallel process of the formation of silver particles on the glass substrates. Bright and dark field TEM images at $300 \mathrm{kV}$ were taken, as well as selected area-electron diffraction (SAED) patterns.

Film thickness was measured using a JEOL model 6400F SEM. For such measurements, the films were coated with chromium, sectioned and dipped into dilute HF solution for $1 \mathrm{~s}$, rinsed, and dried under a heating lamp.

A Cary 500 scan spectrophotometer was used to determine the optical absorption of the films in the wavelength range of $300-1500 \mathrm{~nm}$.

The surface morphology of these films was studied by a DI-Dimension $^{\mathrm{TM}} 3100$ model AFM (Digital Instrument).

The surface chemistry of the films was studied using PHI-5400 x-ray photoelectron spectroscopy at a vacuum of $\sim 10^{-9}$ Torr. A nonmonochromatic $\operatorname{Mg} K \alpha$ x-ray source $(h \nu=1253.6 \mathrm{eV})$ at a power of $250 \mathrm{~W}$ was used for the analysis. Both survey scans and individual high-resolution scans (Ag $3 d, \mathrm{C} 1 s, \mathrm{O} 1 s, \mathrm{Na} 1 s$, and valence band) were recorded. Binding energies have been corrected using adventitious carbon $(\mathrm{C} 1 s$ at $284.6 \mathrm{eV})$ as a reference. ${ }^{38}$ The Auger Scan software from RBD Enterprises was used to facilitate peak deconvolution.

A 1.7 MeV Tandetron Rutherford backscattering system with a ${ }^{4} \mathrm{He}^{++}$beam was used to study the concentration depth profile of silver in the coatings.

An energy dispersive $\mathrm{x}$-ray analyzer (EDAX) attached to a JEOL 6400 scanning electron microscope was used to study the chemical composition of the films, which gave the elemental information for RBS data fitting.

\section{RESULTS}

\section{A. Formation of glassy film and nano-silver particles}

Viscosity control is very important for producing crackfree films. The viscosity-time curve, often known as the gelation curve, describes the gelation behavior of the sol-gel system. Viscosity of the solutions as a function of various silver concentrations and time for gelation is shown in Fig. 1. It is to be noted that it takes a longer time to reach the same viscosity for a lower silver concentration. For instance, it takes only several days for the sol with $2 \mathrm{~mol} \%$ silver to reach gel point, while the one with $0.1 \mathrm{~mol} \%$ silver remains 


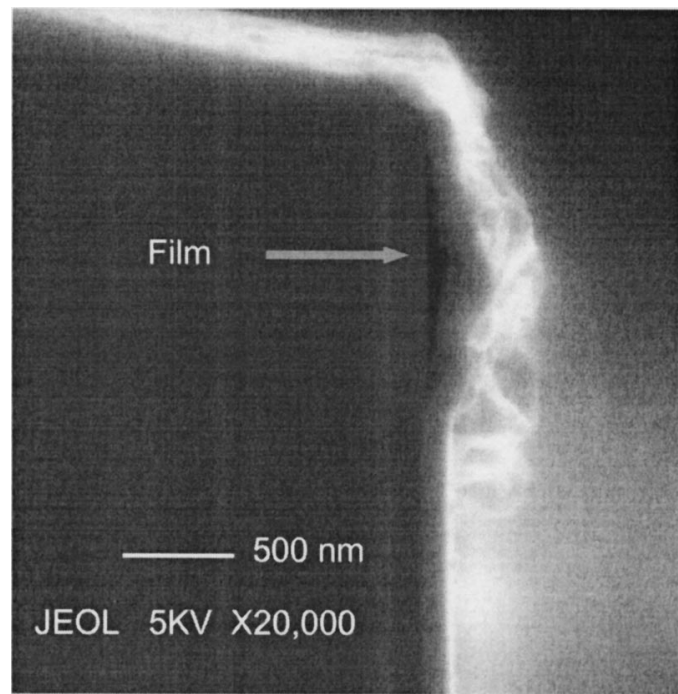

FIG. 2. SEM images of a typical silver silica film on a microscope glass slice, coated with chromium.

liquid even after several weeks. According to Brinker and Scherer, ${ }^{37}$ the presence of salts compresses the double layer around sol particles, reducing the stability of the sol and decreasing the gelation time.

Transparent, uniform, and crack-free films were deposited on microslide glass substrates (soda-lime glass). All films were found to be strongly adherent to the substrates. No peeling was observed through the heat-treatment. There is no change observed before and after conventional Scotchtape tests. The dried films containing silver exhibit a yellowish color. The color gets more intense with increasing silver concentration. After heat-treatment, the color becomes less apparent. At temperature greater than $300{ }^{\circ} \mathrm{C}$, the films become transparent even for the high silver concentration samples.

Figure 2 shows a cross-sectional SEM image of a dried silver silica film with $0.05 \mathrm{~mol} \%$ silver. The film thickness was measured to be $150-200 \mathrm{~nm}$. This is a typical thickness of the dried films for all the silver concentration. A reduction up to $20 \%$ of the thickness was observed for heat-treated films. The films were found to be uniform and dense (free of observable pores) as shown in the SEM images. Figure 3 shows the HRTEM and selected area diffraction (SAD) image of the $\mathrm{SiO}_{2}$ coating with $0.05 \mathrm{~mol} \% \mathrm{Ag}$ on the copper grid. The sizes of the silver particle were about 5-7 nanometers with a fcc structure. The Ag particle size evolution depends on the silver concentration, and the heat-treatment temperature. The silver particle sizes at a higher silver concentration (1 mol \%) after different heat-treatments are shown in the AFM study in the following section.

\section{B. Optical, chemical, and structural characterization of the films}

\section{Optical properties of Ag doped silica films}

The optical absorption data of the sol-gel films with different silver concentrations as a function of different heat treatments are plotted in Fig. 4. As indicated in Fig. 4, the absorption curve with no silver or low silver concentration

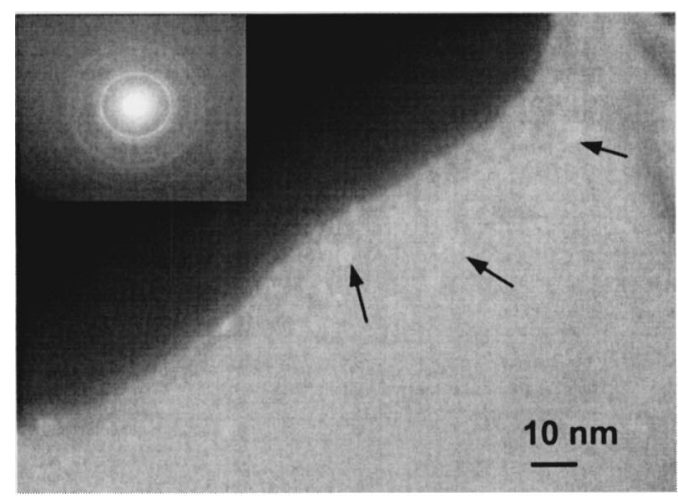

Bright Field

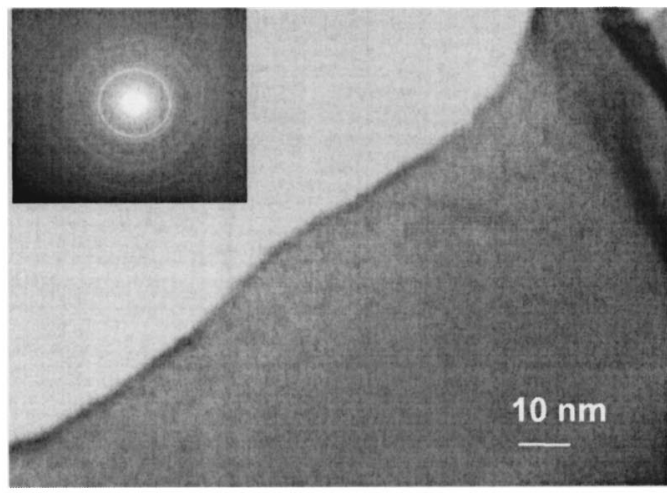

Dark Field

FIG. 3. TEM images of $\mathrm{SiO}_{2}$ gel containing $0.05 \% \mathrm{Ag}$, with inset diffraction patterns of Ag particles.

$(0.1 \mathrm{~mol} \%$ or $0.2 \mathrm{~mol} \%)$ shows a typical fringe pattern observed in weak absorption films. ${ }^{39,40}$ There are only a couple of interference fringes, as the films are very thin (below 200 $\mathrm{nm})$. There is a trend in reduction of the wavelength difference between two absorption maxima. This is due to a decrease in film thickness ${ }^{39}$ with an increase in heat-treatment temperature. There are two factors that affect the fringe patterns, the thickness and the refractive indexes of the films. A detailed study on the fringe patterns of the absorption and reflection data is in progress.

The absorption curves of the films with high silver concentrations $(0.5-2 \mathrm{~mol} \%)$ show an absorption peak between 400 and $460 \mathrm{~nm}$ wavelength, while exhibiting a yellow color of a different degree. With the same heat-treatment temperature, the films with higher silver concentration show increased absorption intensity.

It is observed that the absorption intensity decreases while the heat-treatment temperature increases. While there is noticeable absorption for the dried samples $(0.5-2 \mathrm{~mol} \%$ $\mathrm{Ag}$ ), the intensity of absorption decreases for $200{ }^{\circ} \mathrm{C}$ samples. For samples heated above $300^{\circ} \mathrm{C}$, no distinguishing absorption beyond the fringe pattern is observed. This change is accompanied by the disappearance of the yellowish color of the film. Meanwhile a blueshift is observed comparing the dried samples and the $200{ }^{\circ} \mathrm{C}$ heat-treated samples. 

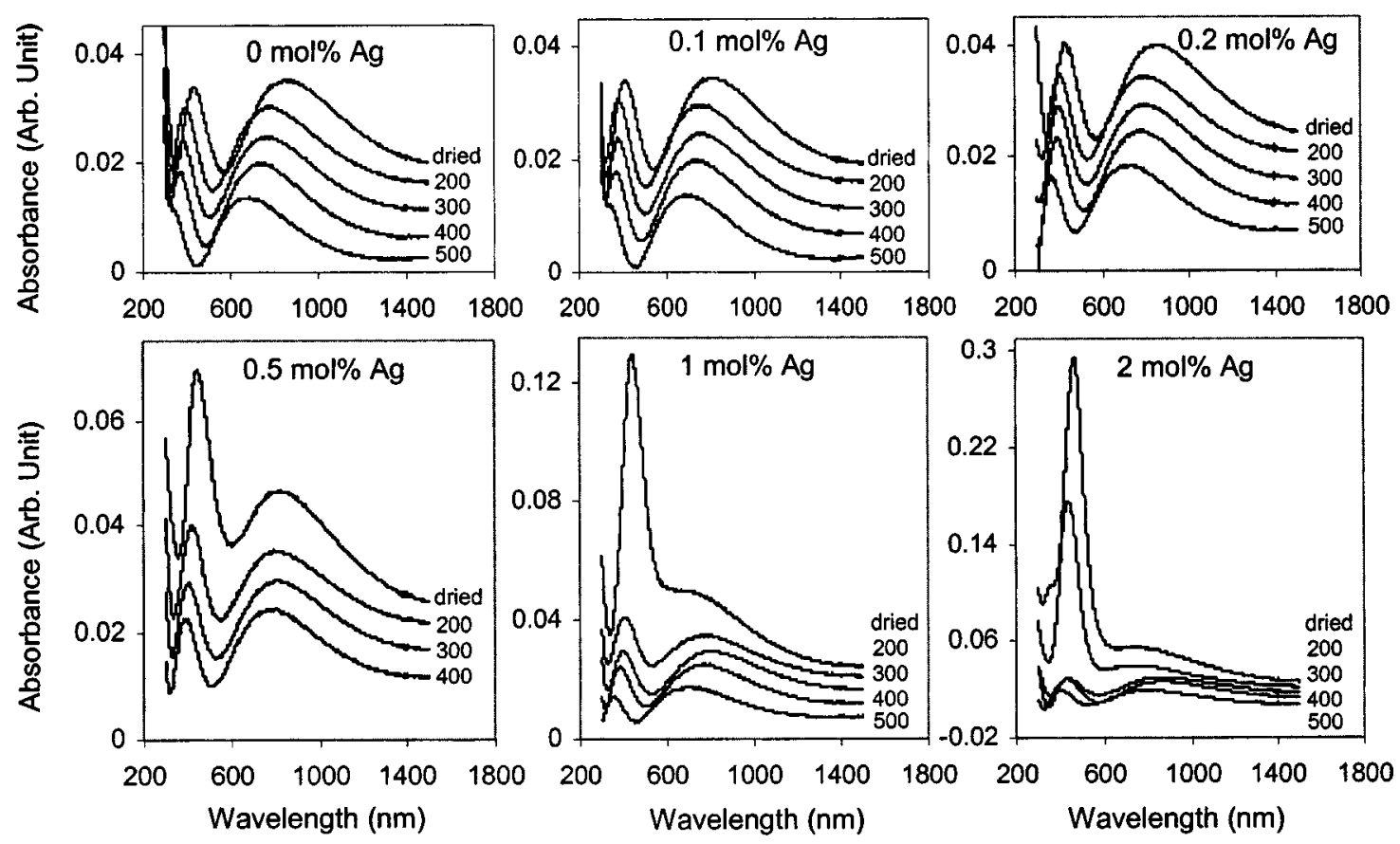

FIG. 4. Optical absorbance spectra for the sol-gel silver-silica films with different silver concentrations after different heat-treatments.

\section{AFM studies of the film surface}

AFM images of dried and heat-treated silica films with 1 mol \% Ag are shown in Fig. 5. For the dried film, needleshaped features are observed on the surface. The dimensions of the particles are around 350 by $60 \mathrm{~nm}$. When the films are heat-treated at $200^{\circ} \mathrm{C}$ for $2 \mathrm{~h}$, the morphology of the surface particle becomes spherical, with diameters from 70 to 100 $\mathrm{nm}$. At $300^{\circ} \mathrm{C}$, a new feature with certain linear orientation starts to develop. At $400{ }^{\circ} \mathrm{C}$, the new feature developed into a dendrite structure on the surface of the film. At $500^{\circ} \mathrm{C}$, the dendrite feature flattens, and more high spots appear on the surface. Another noticeable change in the surface morphology is that the major features on the surface flatten with an increase in temperature. For dried and $200{ }^{\circ} \mathrm{C}$ heat-treated films, the features are higher than $10 \mathrm{~nm}$. From 300 to $500^{\circ} \mathrm{C}$, the main features reduce from $\sim 7$ to $\sim 5 \mathrm{~nm}$. To understand the orientation of the surface features $\left(300-500^{\circ} \mathrm{C}\right)$, AFM imaging (not shown) was performed on the substrate surface. This revealed polishing lines with the same orientation as the surface structure observed in the coating. This suggests that the polishing lines serve as nucleation sites for the subsequently observed surface structures grown after $300^{\circ} \mathrm{C}$ or higher temperature heat-treatment. The change of the surface chemical make-up between 200 and $300^{\circ} \mathrm{C}$ was shown by XPS.

\section{XPS studies on the film surface}

To understand the surface chemical changes, XPS was used to study $1 \mathrm{~mol} \% \mathrm{Ag}$ silica sol-gel films heat-treated at different temperatures. Figure 6 shows the XPS survey scans for the different heat-treatments. Figures 7-10 show detailed XPS scans for Ag $3 d, \mathrm{Na} 1 s, \mathrm{O} 1 s$, and $\mathrm{Si} 2 p$, respectively. From these results, it can be seen that silver is present on the film surface for the dried sample and the one treated at $200^{\circ} \mathrm{C}$. This suggests that the particles observed by AFM at a dried condition (needle shaped) and $200^{\circ} \mathrm{C}$ (sphere-like) are silver particles. Surface silver content decreases as the heat-treatment temperature increases, while sodium appears after heating at $200^{\circ} \mathrm{C}$ or higher. This suggests that the appearance of the new surface feature in Fig. 5 at $300-500^{\circ} \mathrm{C}$ is due to the sodium diffusion as seen from the XPS data. It is also observed that samples with the highest surface $\mathrm{Na}$ concentration $\left(400{ }^{\circ} \mathrm{C}\right)$ exhibit a reduction in binding energies for both $\mathrm{O} 1 s$ and $\mathrm{Si} 2 p$.

In addition to the surface composition changes, the chemical state of silver also varies. In Fig. $7, \mathrm{Ag} 3 d_{5 / 2}$ shifts from $368.0\left(100^{\circ} \mathrm{C}\right)$ to $367.5\left(200^{\circ} \mathrm{C}\right)$ and then to 367 $\left(300^{\circ} \mathrm{C}\right)$. According to the literature, ${ }^{41-43}$ the binding energies of $\mathrm{Ag}, \mathrm{Ag}_{2} \mathrm{O}$, and $\mathrm{AgO}$ are 368.2, 367.8, and $367.4 \mathrm{eV}$, respectively. Detailed deconvolution of $\mathrm{Ag} 3 d$ is shown in Fig. 11. From the deconvolution results, it is observed that the silver chemical state changes from primarily $\mathrm{Ag}^{0}$ for dried sample to mostly $\mathrm{Ag}^{2+}$ after heat treatment at $300{ }^{\circ} \mathrm{C}$. At higher heat-treatment temperatures, the silver concentration on the surface is so low that it could not be detected under the XPS experimental conditions. It is clear that the silver colloids are formed during the drying process, get oxidized while being heat-treated, and eventually diffuse away from the surface.

The lower binding energy of Si $2 p$ at $400{ }^{\circ} \mathrm{C}$ indicates the formation of ionic networks similar to soda glass, as soda glass has a lower Si $2 p$ binding energy, $102.8 \mathrm{eV}$, comparing to that of silica, $103.2 \mathrm{eV}$, or silica gel, $103.4 \mathrm{eV}^{4}{ }^{44}$ The lower binding energy of oxygen $(\mathrm{O} 1 \mathrm{~s})$ is consistent with ionic bonding of $\mathrm{O}$ with $\mathrm{Si}$ and $\mathrm{Na}$. From the above analysis, the surface morphology observed by AFM at higher temperature (above $300^{\circ} \mathrm{C}$ ) is related to the formation of soda silica ionic networks. 

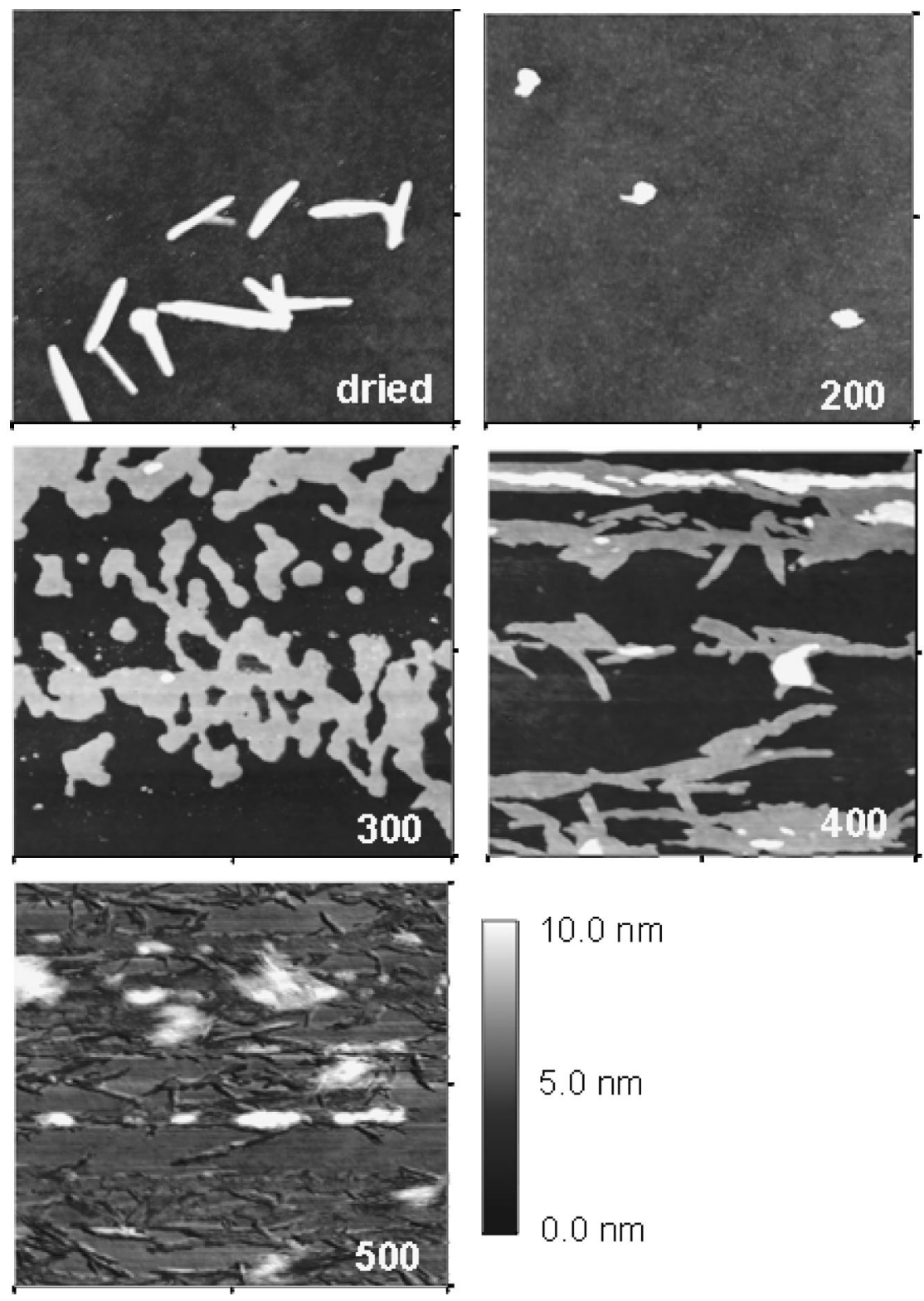

FIG. 5. AFM images $\left(2 \times 2 \mu \mathrm{m}^{2}\right)$ of silica sol-gel films containing $1 \mathrm{~mol} \%$ $\mathrm{Ag}$ after different heat-treatments.

SEM imaging with EDAX reveals the formation of cube-shaped $\mathrm{NaCl}$ particles on the film after heat-treatment at $500{ }^{\circ} \mathrm{C}$ (Fig. 12). It is to be noticed that EDAX is a bulk technique and the focus spot is bigger than the cube particle; thus the other elements in the glass substrate underneath and around the cube particle are also present in Fig. 12(b). The $\mathrm{NaCl}$ could be easily wiped away from the surface resulting in the decrease in surface sodium concentration at $500{ }^{\circ} \mathrm{C}$. The presence of $\mathrm{Cl}$ likely originates from precursor TEOS, which was synthesized from $\mathrm{SiCl}_{4}$.

\section{RBS studies on the sol-gel silica film with $1 \%$ silver}

Changes in silver and sodium surface concentration suggest the interdiffusion of these two species. To further confirm this assumption, RBS was used to study the silver concentration profile in the $1 \%$ Ag-containing sol-gel silica film as a function of heat treatment.
In Fig. 13, the RBS profiles of samples with $1 \%$ silver after varying heat treatments were plotted to compare any changes in the silver profile. Only the front channels corresponding to silver signals are plotted and the silver simulation is overlaid on the graphs. The analysis software RUMP from CGS (Computer Graphics Service) was used to analyze and fit the raw data.

Figure 13 shows that with higher heat-treatment temperature, the silver diffuses from the surface to the interface, and then into the glass substrate. At $100^{\circ} \mathrm{C}$, there are two sharp peaks located within the coating layer indicating the presence of silver on the surface (about $2 \mathrm{~nm}$ from the top) and in the coating (about $20-500 \mathrm{~nm}$ from the top). At $200^{\circ} \mathrm{C}$ the silver profile changes such that silver is diffusing into the glass substrate. As for 300,400 , and $500^{\circ} \mathrm{C}$, the silver concentration at the surface is very low, indicating that most of the silver has diffused into the substrate. 


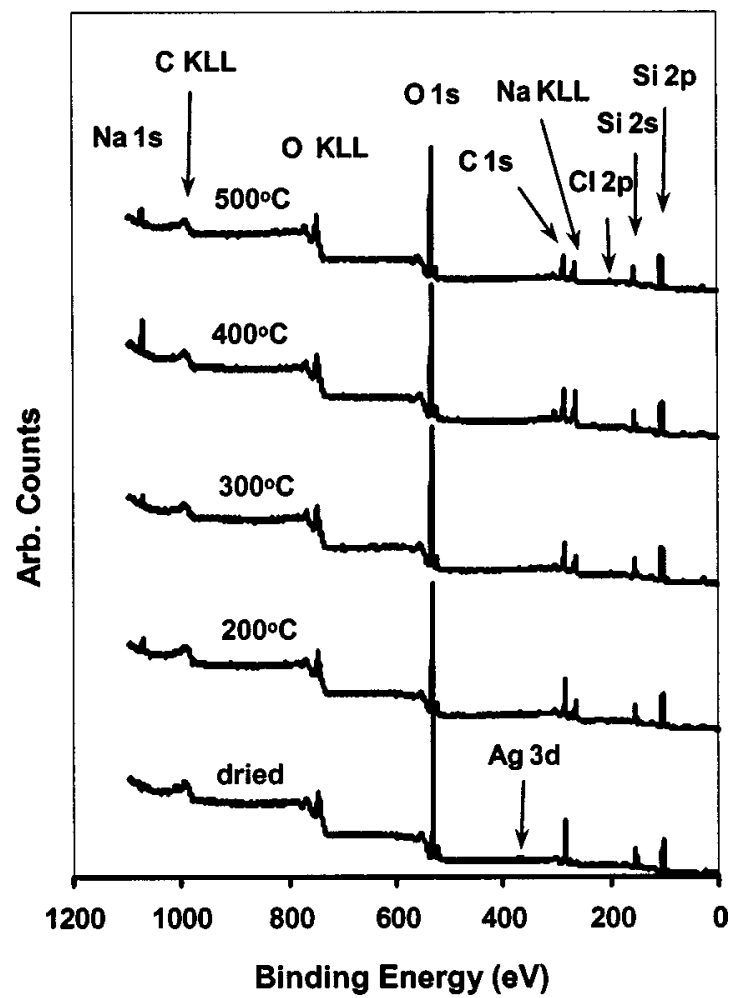

FIG. 6. XPS survey spectra of sol-gel silica films containing $1 \mathrm{~mol} \% \mathrm{Ag}$ after different heat-treatments.

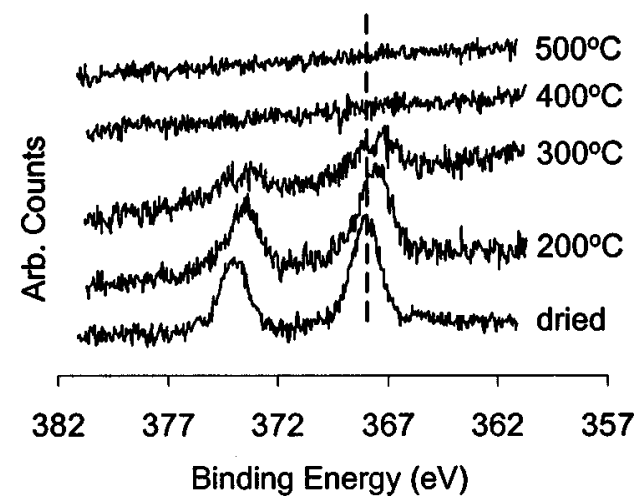

FIG. 7. Ag $3 d$ XPS spectra of sol-gel silica films containing $1 \mathrm{~mol} \% \mathrm{Ag}$ after different heat-treatments.

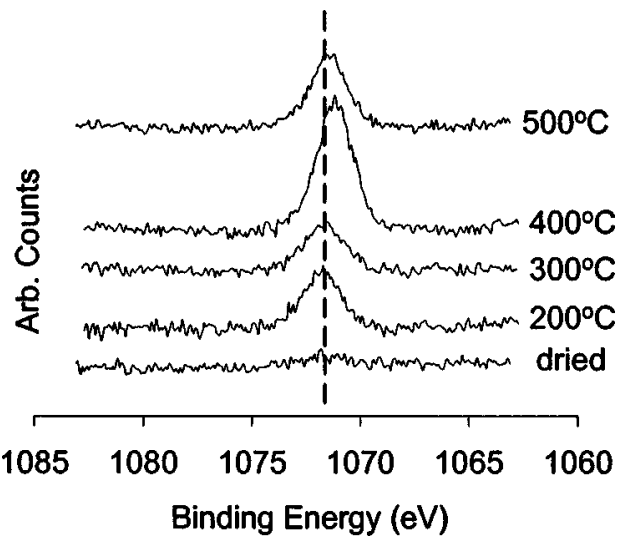

FIG. 8. Na $1 s$ XPS spectra of sol-gel silica films containing $1 \mathrm{~mol} \% \mathrm{Ag}$ after different heat-treatments.

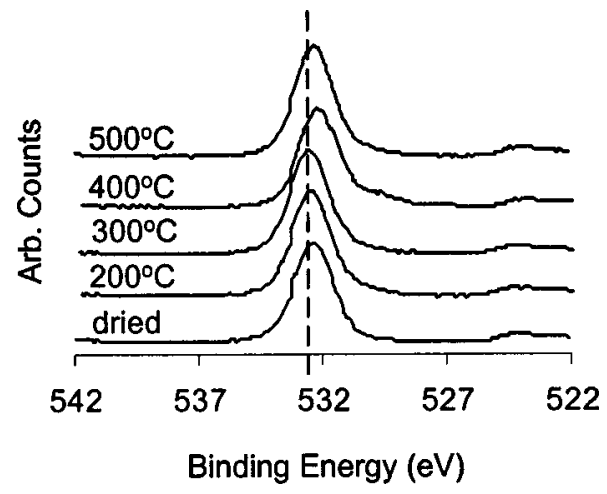

FIG. 9. O $1 s$ XPS spectra of sol-gel silica films containing $1 \mathrm{~mol} \% \mathrm{Ag}$ after different heat-treatments.

\section{DISCUSSION}

The yellowish color we observed in the films of silver colloids is due to the surface-plasmon resonance of silver colloids (Mie resonance). ${ }^{15}$ In general, colloidal suspensions scatter the incident light and, with particles of sufficient size and concentration, the turbidity would cause the glass to lose its transparency. The light scattering is proportional to the reciprocal of the wavelength of the incident light, according to the well-known Rayleigh relationship. ${ }^{45}$ Therefore the extinction caused by scattering is primarily in UV and in the blue end of the visible spectral region. Only with colloidal suspensions of highly absorbing materials, with a very small particle size, will the optical absorption dominate over the light scattering. While metals have high absorptive components in their refractive indices, only a few of them (gold, silver, copper, etc.) show strong wavelength dependence in their absorption property and cause coloration in the visible range.

Theoretically, the visible absorption band of gold and silver metal colloids is attributed to surface plasmon oscillation modes of the conduction electrons which are coupled through the surface (roughness) to the external electromagnetic field. Within the framework of Mie theory, ${ }^{46-48}$ which applies to particles much smaller than the wavelength of light, dipole, and higher order transitions can be treated in principle. Typically only dipole modes are considered, as a result, the width and peak position of the plasmon are independent of the particle size in this approximation. However,

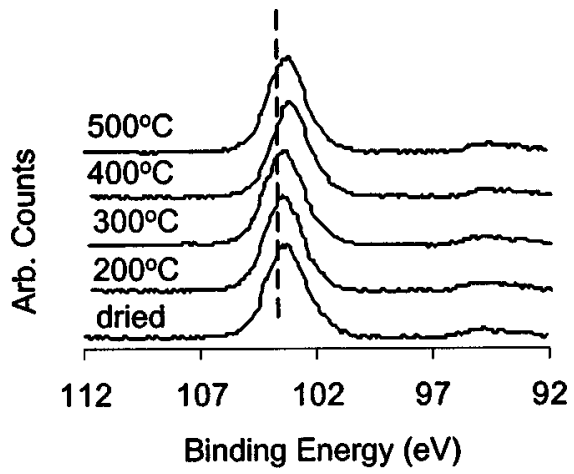

FIG. 10. Si $2 p$ XPS spectra of sol-gel silica films containing $1 \mathrm{~mol} \% \mathrm{Ag}$ after different heat-treatments. 


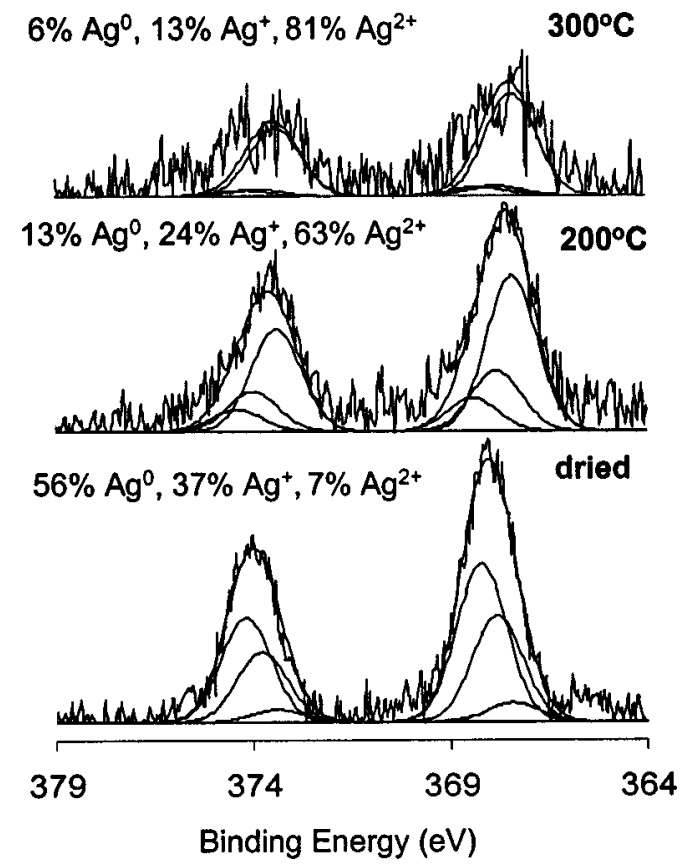

FIG. 11. Deconvolution of $\mathrm{Ag} 3 d$ spectra of sol-gel silica films containing 1 mol \% Ag after heat-treatment at 100,200 , and $300^{\circ} \mathrm{C}$.

in the extinction spectra of monodisperse colloids, one observes that particle size has a strong effect upon peak width and position. A blueshift is often observed as the particle size decreases. ${ }^{49,50}$ The experimental finding can be modeled if the dielectric function of the metal is assumed to be size-dependent. ${ }^{51}$ For particles with diameter $d \geqslant 25 \mathrm{~nm}$, higher order multipole absorption as well as scattering contributes to the extinction spectra. ${ }^{32}$

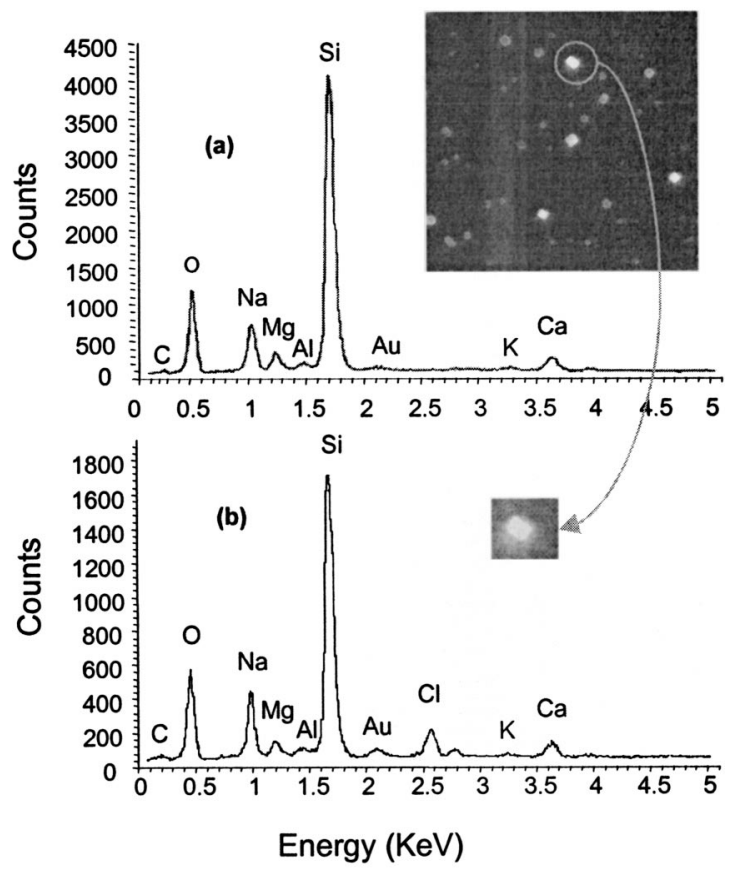

FIG. 12. EDAX spectra of sol-gel silica film with $1 \mathrm{~mol} \%$ silver after $500{ }^{\circ} \mathrm{C}$ heat-treatment: (a) on a large area; and (b) focused on one bright spot.

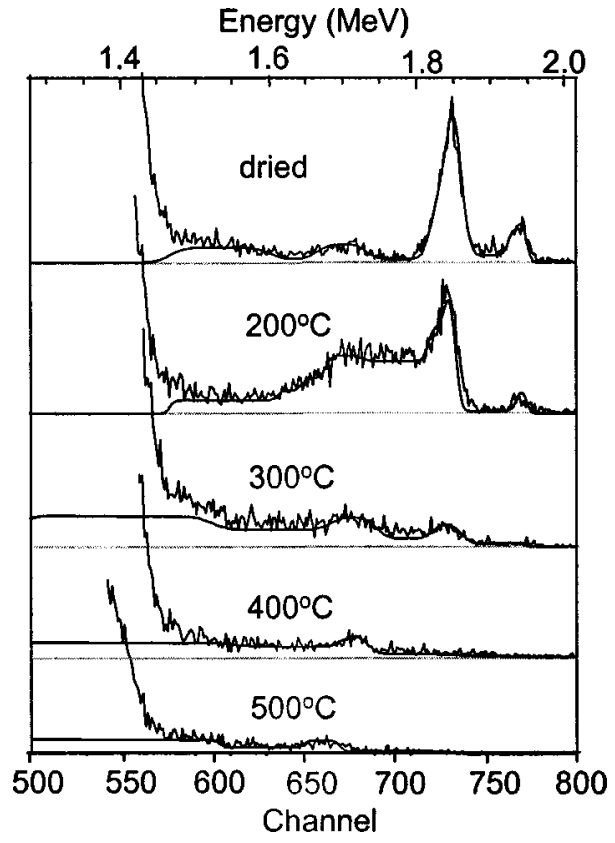

FIG. 13. RBS spectra of $1 \mathrm{~mol} \% \mathrm{Ag}$ sol-gel coating on glass substrate, with silver simulation overlaid.

The surface plasmon absorption peaks for high silver concentration coatings indicated the formation of silver colloids in the glass film. Formation of Ag colloids at low temperatures is confirmed by XPS. Spontaneous silver reduction in sol-gel materials has been reported..$^{31,34,52-54}$ Many researchers contributed the formation of silver colloids to the reduction of $\mathrm{Ag}^{+}$ion by alcohol radicals. Only one group ${ }^{55}$ proposed that ethanol is an inhibiting agent in the formation of Ag colloids, after comparing the optical properties of the sol-gel silver silica gel with and without ethanol in the precursor. Because alcohol is one of the products of condensation reactions, the alcohol radicals can not be eliminated through avoiding alcohol in the starting solution. We favor the reduction mechanism of alcohol radicals, but the formation of silver colloids is a complex process as the sol-gel reaction system is complicated. The starting silver salt concentration, $\mathrm{HNO}_{3}$ concentration, the densification condition of the gel, the UV nucleation effect on silver colloids, and many other factors should be taken into consideration if the mechanism of spontaneous silver reduction is to be completely understood.

The blueshift of the absorption peak is observed in our experiment when heat-treatment temperature is increased from 100 to $200^{\circ} \mathrm{C}$ and is in agreement with the particle size reduction in a $1 \% \mathrm{Ag}$ sample as seen from AFM images. The blueshift effect (of particle size decreasing) in the silver colloid system is well documented. ${ }^{56,57}$

The absorption intensity decrease and discoloration after heat-treatment have been observed in similar sol-gel systems. Menning et al. ${ }^{35}$ observed that silver colloids were oxidized to $\operatorname{Ag}_{x} \mathrm{O}_{y}$ during thermal densification of the coatings and such changes were accompanied by a disappearance of the yellow color of the coatings. Ritzer ${ }^{34}$ observed that the bleaching effect takes places when the Ag-containing silica gel darkened at $60^{\circ} \mathrm{C}$ is heated above $200^{\circ} \mathrm{C}$, and the 
bleaching is completed around $400{ }^{\circ} \mathrm{C}$. Such darkeningbleaching phenomenon was attributed to aggregationdisaggregation of fine silver particles.

According to our XPS measurements, silver in the film is undergoing an oxidation process during heat treatment, resulting in discoloration of the films and the disappearance of the silver absorption peak at temperatures higher than $300^{\circ} \mathrm{C}$. This agrees with Mennig and his coworker's results that silver colloids were oxidized at increasing temperatures. ${ }^{35}$ To determine if oxidation of silver also occurs in silver containing silica gel, Ritzer's experiment was repeated in our research facility and XPS was conducted on both dark and bleached gel powder. Silver $3 d_{5 / 2}$ binding energies were found to be 368.05 and 367.6, respectively. Compared with our XPS results from the films, it is clear that oxidation of silver also occurs in the bleaching of silver containing silica gel.

Both XPS and RBS data show that silver diffuses into the substrate while the samples are being heat-treated. As sodium is a comparably light element, the RBS data does not readily show the concentration profile as it does for silver. However, the XPS results do show that the surface sodium concentration increases as the heat-treatment temperature increases from 100 to $200{ }^{\circ} \mathrm{C}$, where it then remains relatively constant. From the above experimental evidence, we propose a silver-sodium interdiffusion mechanism between the silver in the sol-gel coating and the sodium in the glass substrate. This phenomenon is often observed in ion-exchanged sodium silicate glass. ${ }^{58}$ Comparing Fig. 7 and 8, sodium surface concentration changes more quickly than that of silver due to a higher diffusion coefficient for sodium than silver. ${ }^{59,60}$ Typical experimental values of self-diffusion coefficients for $\mathrm{Ag}$ and $\mathrm{Na}$ are $8.58 \times 10^{-11}$ and 3.71 $\times 10^{-10} \mathrm{~cm}^{2} / \mathrm{s}^{59}$

The diffusion of sodium from substrate into the sol-gel coating can have various effects on the coating. For instance, it was found that the diffusion of sodium from soda-lima glass substrate is detrimental to the photocatalytic activity of the $\mathrm{TiO}_{2}$ sol-gel coating. ${ }^{61}$ Our experimental observation provides evidence for Mennig and his colleagues' supposition that sodium affects the stability of silver colloids on soda-lime glass substrates. ${ }^{35}$ When heating a dried silver silica film on fused silica between 500 and $600^{\circ} \mathrm{C}$, the silver oxide in the film was reduced to $\mathrm{Ag}$ metal particles. While heating the films on soda-lime glass substrate at $400-600{ }^{\circ} \mathrm{C}$ all the Ag colloids are oxidized to silver oxide. As shown in Ref. 62, a remarkable $\mathrm{Na}^{+}$diffusion into the Au-containing coatings above $300{ }^{\circ} \mathrm{C}$ leads to a strong increase in the basicity, ${ }^{63}$ favoring higher oxidation states by thermodynamic arguments. ${ }^{64}$

While our study provides evidence to support Mennig's assumption of sodium diffusion affecting Ag-colloid formation, it also gives evidences against Mennig's other conclusion in the same work. ${ }^{35}$ According to Mennig "a remarkable diffusion of $\mathrm{Ag}^{+}$into the substrate was excluded." Since the coating remained colorless, while as a comparison, the $\mathrm{Ag}^{+}-\mathrm{Na}^{+}$ion-exchange experiment on soda-lime substrate showed a spontaneous Ag-colloid formation and resulting coloration of the glass. The coloration effect is due to the surface plasmon resonance of the conductive electrons in the nano-sized Ag metal particles. The ion-exchange experiment cannot exclude the diffusion of silver ion. In fact our XPS and RBS data show that there is a remarkable diffusion of silver into the substrate.

Comparing AFM, XPS, SEM, and RBS results, we conclude that with an increase in the heat-treatment temperature, the silver particles decrease in size and undergo oxidation in air. On the soda-lime glass substrate, silver oxidation occurs at temperature up to $500{ }^{\circ} \mathrm{C}$, which is well above the thermal decomposition temperature of silver oxide. This is, at least partially due to the substrate effect, caused by sodium diffusing into the coating. The interdiffusion between the silver in the coating and sodium in the substrate occurs at temperatures above $200{ }^{\circ} \mathrm{C}$. These results suggest that tailoring the size of a nano-silver particle is possible through thermal heat-treatment in a reducing environment.

\section{CONCLUSIONS}

Silica films containing nano-silver particles were prepared by the sol-gel process using TEOS and $\mathrm{AgNO}_{3}$ as primary precursors. The sol-gel dip coating technique was found to be an effective way of making optically transparent silver-silica coatings. The silver concentration influenced the viscosity and the gelation process. The optical absorption spectra of the coating exhibited a blueshift when the heattreatment temperature was increased from 100 to $200{ }^{\circ} \mathrm{C}$. This blueshift was due to the reduction in the silver particle size. Meanwhile, the intensity of the silver absorption peak decreased with increasing heat-treatment temperatures, which was caused by the oxidation of silver particles. Interdiffusion between silver in the coating and sodium in the substrate occurred at temperatures above $200^{\circ} \mathrm{C}$. Soda-lime glass substrate has an important influence on the Ag-colloid formation through sodium diffusion from the substrate into the coating, it enhances the stability of silver oxide at high temperatures.

\section{ACKNOWLEDGMENTS}

The authors would like to thank Dr. Richard Vanfleet at Advanced Materials Processing and Analysis Center (AMPAC) at the University of Central Florida (UCF) for performing TEM, and Alex Schwitter at Material Characterization Facility (UCF) for performing SEM. The authors would also like to acknowledge NSF DMR Grant No. 9974129, which supported doctoral student Wenyan Li, the CREOL REU program, (NSF Grant No. 9732420), which supported undergraduate students Gerald Lelong and Laurent Lachal from France, and the NANOPAC REU program (NSF Grant No. 0139614), which supported Edward Megan at the University of Central Florida.

\footnotetext{
${ }^{1}$ P. Mulvaney, MRS Bull. 26, 1009 (2001).

${ }^{2}$ W. H. Armistead and S. D. Stookey, Science (Washington, DC, U.S.) 144, 150 (1964).

${ }^{3}$ R. A. Ganeev, A. I. Ryasnyansky, S. R. Kamalov, M. K. Kodirov, and T. Usmanov, J. Phys. D 34, 1602 (2001).

${ }^{4}$ F. Hache, D. Ricard, and C. Flytzanis, J. Opt. Soc. Am. B 3, 1647 (1986).

${ }^{5}$ S. Vijayalakshmi and H. Grebel, Handbook of Nanostructureed Materials
} 
and Nanotechnology, Volume 4: Optical Properites, edited by H. S. Nalwa (Academic, New York, 2000).

${ }^{6}$ D. Ricard, P. Roussignol, and C. Flytzanis, Opt. Lett. 10, 511 (1985).

${ }^{7}$ G. W. Arnold, G. De Marchi, F. Gonella, P. Mazzoldi, A. Quaranta, G. Battaglin, M. Catalano, F. Garrido, and R. F. Haglund, Nucl. Instrum. Methods Phys. Res. B 116, 507 (1996).

${ }^{8}$ A. L. Stepanov, D. E. Hole, and P. D. Townsend, Nucl. Instrum. Methods Phys. Res. B 166-167, 882 (2000).

${ }^{9}$ G. Battaglin, Nucl. Instrum. Methods Phys. Res. B 116, 102 (1996).

${ }^{10}$ F. Garrido, F. Caccavale, F. Gonella, and A. Quaranta, Pure Appl. Opt. 4, 771 (1995).

${ }^{11}$ E. Borsella, E. Cattaruzza, G. De Marchi, F. Gonella, G. Mattei, P. Mazzoldi, A. Quaranta, G. Battaglin, and R. Polloni, J. Non-Cryst. Solids 245, 122 (1999).

${ }^{12}$ B. Samuneva, Y. Dimitriev, V. Dimitrov, E. Kashchieva, and G. Encheva, J. Sol-Gel Sci. Technol. 13, 969 (1998).

${ }^{13}$ F. Hache, D. Ricard, and C. Flytzanis, J. Opt. Soc. Am. B 3, 1647 (1986).

${ }^{14}$ A. Licciulli, C. Massaro, L. Tapfer, G. De, M. Catalano, G. Battaglin, P. Mazzoldi, and C. Meneghini, J. Non-Cryst. Solids 194, 225 (1996).

${ }^{15}$ M. A. Garcia, S. E. Paje, J. Llopis, M. A. Villegas, and J. M. Fernandez Navarro, J. Phys. D 32, 975 (1999).

${ }^{16}$ G. Mitrikas, C. C. Trapalis, and G. Kordas, J. Non-Cryst. Solids 286, 41 (2001).

${ }^{17}$ Y. Hosoya, T. Suga, T. Yanagawa, and Y. Kurokawa, J. Appl. Phys. 81, 1475 (1997).

${ }^{18}$ R. Trbojevich, N. Pellegri, A. Frattini, O. de Sanctis, P. J. Morais, and R. M. Almeida, J. Mater. Res. 17, 1973 (2002).

${ }^{19}$ T. Gacoin, F. Chaput, and J. P. Boilot, J. Sol-Gel Sci. Technol. 2, 679 (1994).

${ }^{20}$ Y. Katayama, M. Sasaki, and E. Ando, J. Non-Cryst. Solids 178, 227 (1994).

${ }^{21}$ P. Innocenzi, Proc. SPIE 2288, 87 (1994).

${ }^{22}$ S. Sakka, H. Kozuka, and G. Zhao, Proc. SPIE 2288, 108 (1994).

${ }^{23}$ J. Y. Tseng, C.-Y. Li, T. Takada, C. L. Lechner, and J. D. Mackenzie, Proc. SPIE 1758, 612 (1992).

${ }^{24}$ H. Kozuka, G. Zhao, and S. Sakka, J. Sol-Gel Sci. Technol. 2, 741 (1994).

${ }^{25}$ B. Kutsch, O. Lyon, M. Schmitt, M. Mennig, and H. Schmidt, J. NonCryst. Solids 217, 143 (1997).

${ }^{26}$ S. Szu, C.-Y. Lin, and C.-H. Lin, J. Sol-Gel Sci. Technol. 2, 881 (1994).

${ }^{27}$ M. Mennig, M. Schmitt, B. Kutsch, and H. Schmidt, Proc. SPIE 2288, 120 (1994).

${ }^{28}$ J. M. Tour, S. L. Pendalwar, and J. P. Cooper, Chem. Mater. 2, 647 (1990).

${ }^{29}$ A. Hinsch and A. Zastrow, J. Non-Cryst. Solids 147\&148, 579 (1992).

${ }^{30}$ M. Zayat, D. Einot, and R. Reisfeid, J. Sol-Gel Sci. Technol. 10, 67 (1997).

${ }^{31}$ M. Mennig, J. Spanhel, H. Schmidt, and S. Betzholz, J. Non-Cryst. Solids 147\&148, 326 (1992).

${ }^{32}$ S. Schneider, K. Pöppl, G. Sauer, and P. Matousek, CLRC Rutherford Appleton Laboratory Annual Report 1999/2000, RAL Report No. RALTR-2000-034, 105-106 (unpublished).

${ }^{33}$ H. Kozuka, G. Zhao, and S. Sakka, Bull. Inst. Chem. Res., Kyoto Univ. 72, 209 (1994).
${ }^{34}$ B. Ritzer, M. A. Villegas, and J. M. Fernandez Navarro, J. Sol-Gel Sci. Technol. 8, 917 (1997).

${ }^{35}$ M. Mennig, M. Schmitt, and H. Schmidt, J. Sol-Gel Sci. Technol. 8, 1035 (1997).

${ }^{36}$ M. Mennig, K. Endres, M. Schmitt, and H. Schmidt, J. Non-Cryst. Solids 218, 373 (1997).

${ }^{37}$ C. J. Brinker and G. W. Scherer, Sol-Gel Science: The Physics and Chemistry of Sol-Gel Processing (Academic, San Diego, 1990).

${ }^{38}$ T. L. Barr and S. Seal, J. Vac. Sci. Technol. A 13, 1239 (1995).

${ }^{39}$ E. Marquez, J. Ramirez-Malo, P. Villares, R. Jimenez-Garay, P. J. S. Ewen, and A. E. Owen, J. Phys. D 25, 535 (1992).

${ }^{40}$ J. J. Ruiz-Perez, J. M. Gonzalez-Leal, D. A. Minkov, and E. Marquez, J. Phys. D 34, 2489 (2001).

${ }^{41}$ J. S. Hammond, S. W. Gaarenstroom, and N. Winograd, Anal. Chem. 47, 2194 (1975).

${ }^{42}$ S. W. Gaarenstroom and N. Winograd, J. Chem. Phys. 67, 3500 (1977).

${ }^{43}$ G. Schoen, Acta Chem. Scand. (1947-1973) 27, 2623 (1973).

${ }^{44}$ C. D. Wagner, D. E. Passoja, H. F. Hilery, T. G. Kinisky, H. A. Six, W. T. Jansen, and J. A. Taylor, J. Vac. Sci. Technol. 21, 933 (1982).

${ }^{45}$ R. H. Doremus, J. Chem. Phys. 40, 2389 (1964).

${ }^{46}$ G. Mie, Ann. Phys. (Leipzig) 25, 377 (1968).

${ }^{47}$ J. C. Maxwell-Garnett, Philos. Trans. R. Soc. London, Ser. A 203, 385 (1904).

${ }^{48}$ H. C. Van de Hulst, Light Scattering by Small Particles (Wiley, New York, 1957).

${ }^{49}$ G. L. Hornyak, C. J. Patrissi, and C. R. Martin, J. Phys. Chem. B 101, 1548 (1997)

${ }^{50}$ J.-T. Lue, J. Phys. Chem. Solids 62, 1599 (2001).

${ }^{51}$ U. Kreibig and M. Vollmer, Optical Properties of Metal Clusters (Springer-Verlag, Berlin, 1995).

${ }^{52}$ M. Mennig, H. Schmidt, and C. Fink-Straube, Proc. SPIE 1590, 152 (1991).

${ }^{53}$ P.-W. Wu, B. Dunn, V. Doan, B. J. Schwartz, E. Yablonovitch, and M. Yamane, J. Sol-Gel Sci. Technol. 19, 249 (2000).

${ }^{54}$ A. Henglein, Th. Linnert, and P. Mulvaney, Ber. Bunsenges. Phys. Chem. 94, 1449 (1990).

${ }^{55}$ V. M. Renteria, A. Campero, and J. Garcia M., J. Sol-Gel Sci. Technol. 13, 663 (1998).

${ }^{56}$ K. Akamatsu, S. Takei, M. Mizuhata, A. Kajinami, S. Deki, S. Takeoka, M. Fujii, S. Hayashi, and K. Yamamoto, Thin Solid Films 359, 55 (2000).

${ }^{57}$ S. Banerjee and D. Chakravorty, Appl. Phys. Lett. 72, 1027 (1998).

${ }^{58}$ B. Messerschmidt, B. L. McIntyre, S. N. Houde-Walter, R. R. Andre, and C. H. Hsieb, Opt. Mater. 7, 165 (1997).

${ }^{59}$ A. Belkhir, IEEE J. Quantum Electron. 35, 306 (1999).

${ }^{60}$ R. H. Doremus, J. Phys. Chem. 68, 2212 (1964).

${ }^{61}$ J. Yu and X. Zhao, MRS Bull. 35, 1293 (2000).

${ }^{62}$ B. Kutsch, M. Schmitt, M. Mennig, and H. Schmidt, 4th Saar-Lor-Lux Meeting on Functional Advanced Materials, 1994, Metz (unpublished).

${ }^{63}$ H. Scholze, Glass-Natur, Struktur und Eigenschaften (Springter-Verlag, Berlin, 1977).

${ }^{64}$ W. Stegmayer and A. Dietzel, Glastech. Ber. 18, 297 (1940). 